\title{
Technical and economic analysis of the combined-cycle plant with back-pressure steam turbine
}

\author{
Aleksandra Antonova ${ }^{1, *}$, Aleksandr Vorobiev $^{1}$, and Artem Uvarov ${ }^{1}$ \\ ${ }^{1}$ National Research Tomsk Polytechnic University, 634050 Tomsk, Russia
}

\begin{abstract}
The cogeneration combined-cycle gas turbine plant with backpressure steam turbine is considered. A simple circuit of the plant increases its reliability, and the use of optimal temperatures of the heating and return water allows obtaining the highest thermal efficiency of the plant taking into account the ratio of its electric and heat power. The technical and economic efficiency of the combined-cycle plant with back-pressure steam turbine is studied to estimate the capital investment. The parameters and conditions to maximize the net present value growth relative to the base version are determined.
\end{abstract}

\section{Introduction}

One of the most effective energy saving technologies is the improvement of existing heat and mass exchange units [1-4]. Combined-cycle technologies have occupied a leading position in heat power engineering due to high heat efficiency and environmental friendliness. Generating equipment in domestic thermal power plants and in the world energy is mainly implemented through combined-cycle power plants (CCPP) [5]. In the most efficient binary-cycle CCPP with bottoming cycle and is called a combined cycle gas turbine (CCGT) plant. The exhaust heat of gas turbine (GT) is recovered in a heat recovery steam generator (HRSG) for generation of superheated steam, which then flows to the steam bottoming cycle. The efficiency of these CCGTs based on high-temperature GT reaches $60 \%$ and higher $[6,7]$. Higher levels of heat efficiency are obtained in cogeneration combined-cycle plants supplied with different cycles and circuits. One of the versions of this plant is CCGT with a back-pressure steam turbine (CCGT-BP) [8].

\section{CCGT with a back-pressure steam turbine}

In CCGT-BP, the exhaust GT gas heat is recovered in HRSG in two sections of the heating cycle: upon supply of the superheated steam (hot water, steam generation, superheating) and during heating the return water in the HRSG back-end surfaces. The heat generated by the exhaust steam is transferred to the steam or to the water supplied directly to the network.

\footnotetext{
*Corresponding author: anton@tpu.ru
} 
CCGT-BP is very simple in its design since no several steam pressure levels and reheating are required. Fig. 1 shows a CCGT-BP schematic diagram to supply heat to heat and hot water consumers and for household needs.

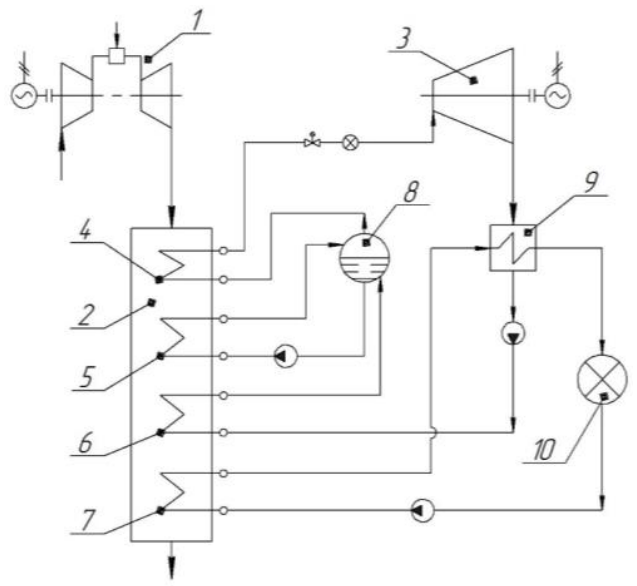

Fig. 1. Schematic diagram of CCGT with a back-pressure steam turbine: GT (1); HRSG (2); steam turbine (3); steam superheater (4); evaporator (5); economizer (6); GWNH (7); drum (8); network heater (NH) (9); heat consumer (10).

The efficiency of HRSG and that of the whole plant can be increased through deep heat recovery due to reduced exhaust gas temperature during transmission of heat to the return heating water in the gas-water network heater $(\mathrm{GWNH})$. The temperature chart of the heat supply system is crucial for the performance of the CCGT-BP steam section, since the temperature of the heating water affects the pressure of the turbine exhaust steam; its value is close to the atmospheric pressure or exceeds it.

\section{Thermal efficiency of CCGT-BP}

The thermal efficiency of CCGT-BP can be estimated using the so-called total efficiency of CCGT, which shows the portion of the fuel heat utilized in the plant.

Utilized heat is the sum of the CCGT electric power $N_{E}$, and heat power transferred to heat consumers $Q_{H C}$. The total efficiency of CCGT

$$
\eta_{C C G T}=\frac{N_{E}+Q_{H C}}{Q_{C C}}
$$

where $Q_{C C}$ is the fuel heat input to the working fluid in the GT combustion chamber.

In turn, the CCGT electric power is the sum of two summands

$$
N_{E}=N_{E}^{G T}+N_{E}^{S T},
$$

where $N_{E}^{G T}$ and $N_{E} S T$ are the electric power of gas and steam turbine.

Transform the formula of the CCGT total efficiency

$$
\eta_{C C G T}=\frac{N_{E}+Q_{H C}}{Q_{C C}}=\frac{N_{E}^{G T}+N_{E}^{S T}+Q_{H C}}{Q_{C C}}=\frac{N_{E}^{G T}}{Q_{C C}}+\frac{N_{E}^{G T}+Q_{H C}}{Q_{C C}}
$$

Transforming expression (3), we obtain 


$$
\eta_{C C G T}=\frac{N_{E}^{G T}}{Q_{C C}}+\frac{N_{E}^{S T}+Q_{H C}}{Q_{C C}}=\eta_{G T}+\frac{Q_{C C} \cdot\left(1-\eta_{G T}\right) \cdot \eta_{H R S G}}{Q_{C C}}=\eta_{G T}+\left(1-\eta_{G T}\right) \cdot \eta_{H R S G}
$$

Thus, the CCGT total efficiency is

$$
\eta_{C C G T}=\eta_{G T}+\left(1-\eta_{G T}\right) \cdot \eta_{H R S G}
$$

This formula lacks the efficiency of the steam turbine or any other factor that indicates its heat efficiency. Hence, the effectiveness of the combined-cycle plant with a backpressure turbine does not depend on the steam cycle (SC) efficiency. This can be attributed to the fact that $\mathrm{SC}$ works without cycle losses: the exhaust steam condensation heat is fully utilized to cover the consumers' heat demands.

In addition to the total efficiency, the most important characteristic of the CCGT-BP heat efficiency is the power ratio $N_{E} S T / Q_{H C}$.

The aim is to study the effect of a number of factors on CCGT-BP heat efficiency. These factors are as follows: temperature of the heating water $t_{h w}$, temperature of the return water $t_{r w}$, initial steam pressure $p_{0}$, initial steam temperature $t_{0}$.

In accordance with the recommendations [9], a number of variables are taken: temperature difference at the evaporator of $5^{\circ} \mathrm{C}$, subcooling to the saturation temperature in network heater of $5{ }^{\circ} \mathrm{C}$, temperature difference at the $\mathrm{GWNH}$ of $5{ }^{\circ} \mathrm{C}$, initial steam temperature $t_{0}$.

The design conditions for CCGT-BP imply its operation at ambient temperature of $-40{ }^{\circ} \mathrm{C}$ (temperature specified for heating system design in Tomsk). The key GT characteristics are calculated with regard to its energy parameters; air heating to $3.4{ }^{\circ} \mathrm{C}$ through air recirculation at the compressor outlet is considered. The Siemens SGT5-4000F gas turbine was used as the CCGT-BP basis. The GT performance parameters at external temperature of $-40{ }^{\circ} \mathrm{C}$ are as follows: GT load is $100 \%$, electrical efficiency is $35.37 \%$, electric power is $247.6 \mathrm{MW}$, exhaust gas temperature is $594.8^{\circ} \mathrm{C}$, exhaust gas flow is $644.9 \mathrm{~kg} / \mathrm{s}$.

The model was made in "MathCad" software and tested in the special "Thermoflex" complex.

In this study, the total capital investment cannot be taken as a criterion for the solution choice since the electric power of the steam turbine varies considerably. Therefore, to choose the best option, a net present value or net value gain relative to the base case should be used [10].

\section{Results of the design efficiency of CCGT-BP}

\subsection{Effect of heating water temperature}

The results of calculations for the CCGT-BP steam section performed at different heating water temperature are shown in Fig. 2. The return water temperature is $60{ }^{\circ} \mathrm{C}$; the initial parameters of steam: $5.0 \mathrm{MPa}$ and $540{ }^{\circ} \mathrm{C}$. 


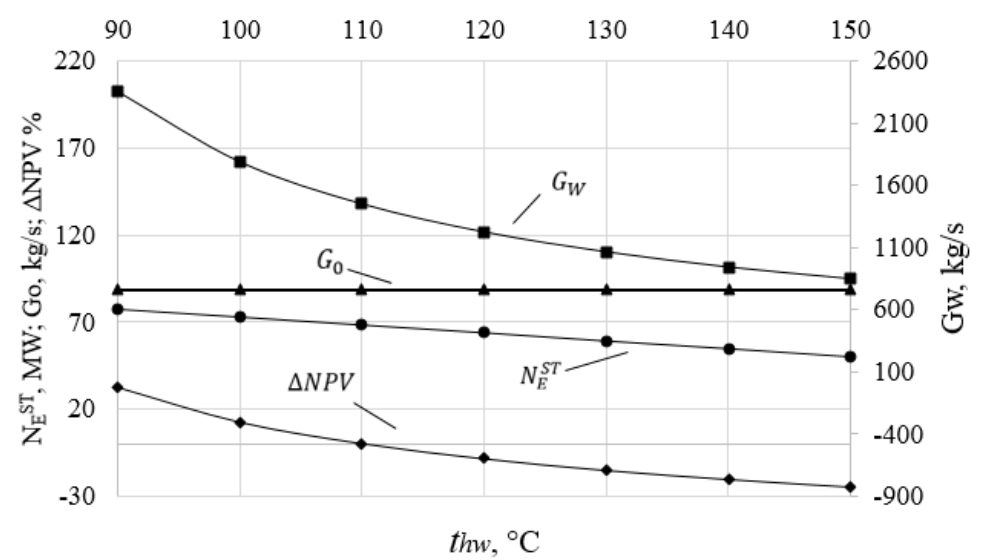

Fig. 2. Variation in CCGT-BP parameters against the temperature of the heating water.

\subsection{Effect of return water temperature}

The results of the calculations carried out for different values of the return water temperature are shown in Fig. 3. The heating water temperature is $110{ }^{\circ} \mathrm{C}$; the initial parameters of steam: $5.0 \mathrm{MPa}$ and $540{ }^{\circ} \mathrm{C}$.

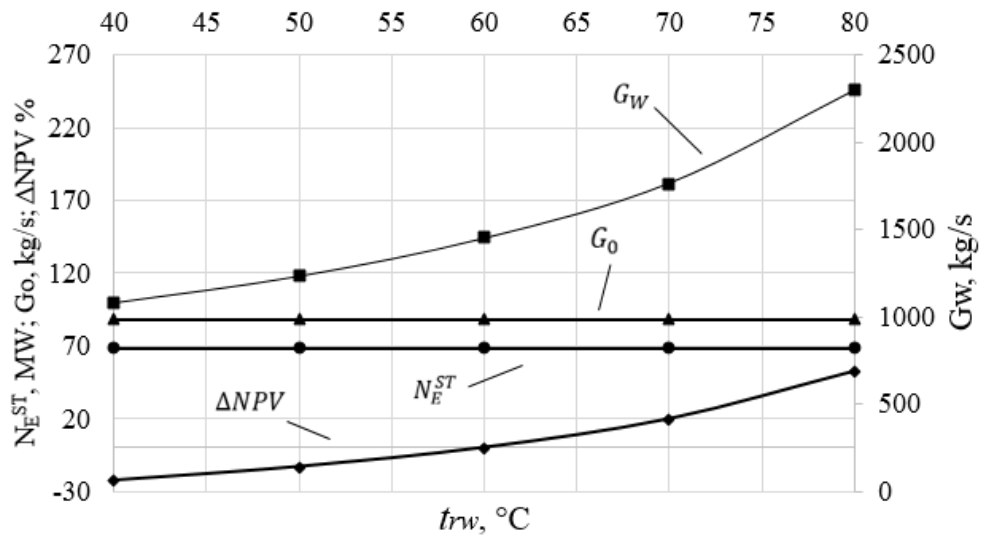

Fig. 3. Variation in CCGT-BP parameters against the temperature of the return water.

\subsection{Effect of initial parameters of steam on CCGT-BP efficiency}

The calculation results for different values of initial parameters of steam are shown in Fig. 4. The heating water temperature is $110^{\circ} \mathrm{C}$, and the return water temperature is $60^{\circ} \mathrm{C}$. 


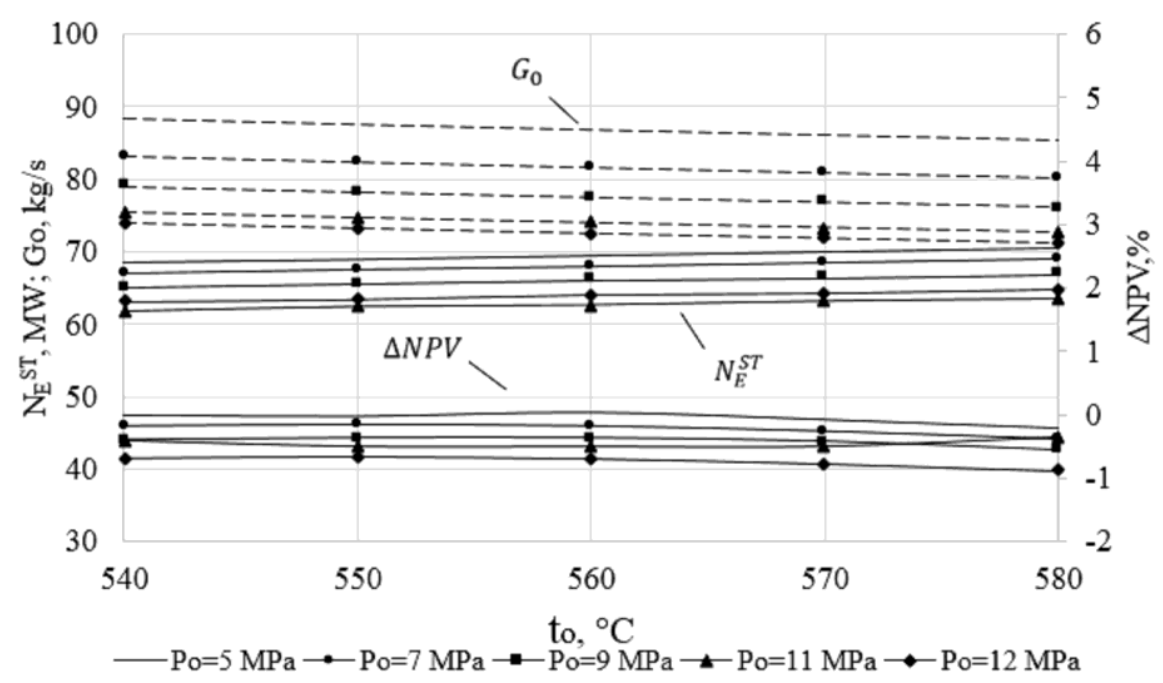

Fig. 4. Variation in CCGT-BP parameters against initial parameters of steam.

As can be seen from Fig. 4, the initial steam parameters have a negligible effect on the CCGT-BP basic parameters.

Taking into account the impact of ecological benefits of the installation can be using the software complex [11].

\section{Conclusions}

The efficient performance of the steam section does not affect the CCGT-BP heat efficiency since bottoming cycle runs without cycle losses. In addition, simple circuit of the plant due to single-loop bottoming cycle and lack of steam reheating increases the CCGTBP reliability.

The values of the CCGT-BP total efficiency and that of HRSG do not depend on temperature of the heating water since useful power of HRSG does not change due to constant temperature of gases at its inlet and outlet. Reduced temperature of the heating water results in increased efficiency of the investment in the project as a result of increased electric power of the steam turbine unit and increased gain in the net present value $\triangle$ NPV.

When the return water temperature grows from $40{ }^{\circ} \mathrm{C}$ to $80{ }^{\circ} \mathrm{C}$, the HRSG efficiency drops by $7 \%$, which reduces the amount of the delivered heat by $8.5 \%$ and reduces the total value of the CCGT-BP efficiency by $4.3 \%$. In addition, as temperature grows, the net present value $\triangle \mathrm{NPV}$ changes by $74.8 \%$.

The growth of the initial temperature in that range (by $7.4 \%$ ) leads to a decrease in the live steam flow. At increased temperature, the electric power slightly increases regardless of the initial pressure level, and the electric power gain is 1.6-1.9 MW. The value of $\triangle$ NPV relative to the base version is negligibly negative in all the cases, and it does not virtually change.

At increased initial steam pressure, the parameter of the heat transferred to each surface of HRSG, except for GWNH, decreases. As a result, the steam flow to the turbine reduces and the electric power decreases. At increased pressure, the total capital investment remains virtually unchanged: at pressure increased in the above range, it reduces by $0.73 \%-0.75 \%$. The NPV growth is not observed.

Based on the above, it should be noted that the technical and economic efficiency of CCGT-BP largely depends on the temperature chart of the heating system, i.e., on 
temperatures of the heating and return water. Variation in the initial parameters of steam has a negligible impact on the CCGT-BP performance parameters.

\section{References}

1. A.V. Dmitriev, O.S. Dmitrieva, I.N. Madyshev, Therm. Eng., 63 (9), 674 (2016), DOI: 10.1134/S0040601516080036

2. S. Lavrinenko, P. Polikarpov, A. Matveeva, V. Martyshev, MATEC Web of Conf., 110, 01049 (2017), DOI: 10.1051/matecconf/201711001049

3. D. Gvozdyakov, V. Gubin, S. Shvab, A. Tanishev, MATEC Web of Conf., 72, 01037 (2016)

4. E. Pavelyev, S. Lavrinenko, MATEC Web of Conf., 72, 01085 (2016), DOI: $10.1051 /$ matecconf $/ 20167201085$

5. G. Olkhovsky, V. Trushechkin, Thermal power plants, 1, 2 (2013)

6. A.M. Antonova, A.V. Vorobiev, A.S. Orlov, MATEC Web of Conf., 23, 01069 (2015), DOI: $10.1051 /$ matecconf $/ 20152301069$

7. A. Uvarov, A. Antonova, A. Vorobiev, MATEC Web of Conf., 37, 01062 (2015), DOI: $10.1051 /$ matecconf $/ 20153701062$

8. A. Gushchin, V. Torzhkov, Turbiny i dizeli, 7, 16 (2007)

9. A. Trukhniy, Parogazovyye ustanovki elektrostantsiy (MEI, Moscow, 2013)

10. A. Devyanin, Optimization of parameters of the cycle for three-loop combined-cycle plants (Abstract of diss., Moscow, 2009)

11. A.V. Vorobiev, E.M. Dutova, A.S. Latyshev, MATEC Web of Conf., 72, 01125 (2016), DOI: 10.1051/matecconf/20167201125 